\title{
A Strategic Risk Management Framework for Multinational Enterprise
}

Juul Andersen, Torben

Document Version

Final published version

Publication date:

2005

License

CC BY-NC-ND

Citation for published version (APA):

Juul Andersen, T. (2005). A Strategic Risk Management Framework for Multinational Enterprise.

Link to publication in CBS Research Portal

\section{General rights}

Copyright and moral rights for the publications made accessible in the public portal are retained by the authors and/or other copyright owners and it is a condition of accessing publications that users recognise and abide by the legal requirements associated with these rights.

\section{Take down policy}

If you believe that this document breaches copyright please contact us (research.lib@cbs.dk) providing details, and we will remove access to the work immediately and investigate your claim. 


\title{
A Strategic Risk Management Framework for Multinational Enterprise
}

\author{
Torben J. Andersen
}

SMG WP 3/2005

September 2005 
SMG Working Paper No. 3/2005

September 2005

ISBN: TBA

Center for Strategic Management and Globalization Copenhagen Business School

Porcelænshaven 24

2000 Frederiksberg

Denmark

www.cbs.dk/smg 


\title{
A Strategic Risk Management Framework for Multinational Enterprise
}

\author{
Torben Juul Andersen \\ Center for Strategic Management \& Globalization \\ Copenhagen Business School \\ Porcelænshaven 24, 2.53 \\ DK-2000 Frederiksberg \\ Denmark \\ Phone: +45 3815-2514 \\ Email: tja.lpf@cbs.dk
}

September 2005

Keywords: Computerized simulations; Derivative instruments; Real option structures; Strategic management process 


\title{
A Strategic Risk Management Framework for Multinational Enterprise
}

\begin{abstract}
:
Liberalizations of international trade and improvements in communication and information technologies allow companies to organize around extensive multinational structures of cross-border sourcing networks. In a freely interacting market setting multinational enterprise is exposed to financial and economic risks that can be monitored within conventional reporting systems and managed through use of various derivative instruments. All the while, a dispersed multinational structure can be vulnerable to disruptions caused by changing economic conditions, competitive moves, and geopolitical developments as well as natural disasters and terrorist events that are difficult to forecast. Consequently, current risk management techniques span from conventional gap analyses and quantitative value-at-risk measures of market-related exposures to more qualitative assessments of competitive exposures and low-frequency high-impact disaster events based on scenario analyses. Hence, there is a need to consider risk management approaches that integrate relatively transparent financial exposures with the consequences of uncertain and hard-to-quantify event risks. This paper outlines the contours of such a strategic risk management framework incorporating conventional exposure measures and simulation techniques to assess vulnerability and responsiveness in a turbulent global setting.
\end{abstract}


As international trade is liberalized there has been a steady increase in commercial cross border transactions that has opened for new ways to exploit scale and scope economies in multinational structures. The increased cross border interaction imposes financial and economic exposures on multinational enterprise and the associated increase in market dynamics requires that corporations respond effectively to changing competitive conditions. Use of new communication and information technologies have reduced the meaning of geographical distance and made it possible to coordinate planning, manufacturing, sourcing, distribution, etc., across corporate entities dispersed throughout the globe. A globally networked organization can exploit factor cost advantages and obtain access to regional competencies and diverse human resources. However, the internationalization of corporate activities is also enforcing environmental, competitive, geo-political, and man-made risk factors. Locating operational platforms in different overseas markets creates new exposures including sovereign risks, natural phenomena, terrorism events, etc. There are a variety of risks at play in corporations that operate in a global setting and management must try to cope effectively with all the associated exposures.

This paper discusses different types of risk that expose multinational enterprise operating in a global context and considers integrative approaches to manage the diverse exposures. The paper is structured as follows. First, it provides an overview of different risk factors that may affect multinational business activities and indicate ways to measure and monitor the associated exposures. Then an extended risk management process is introduced to deal with the diverse exposures on an integrated basis and the potential for alternative risk management solutions is considered. Finally, the paper outlines a strategic risk management perspective as conducive to deal more effectively with multinational risk exposures under the turbulence of global market environments.

\section{$2 \quad$ Risk exposures and hedging}

Risk can be conceived in various ways. A common interpretation in finance is based on variability in returns, which renders the construct susceptible to measurement, e.g., indicated by the standard deviation in market values. Another interpretation reflects adverse economic effects from different incidents, which is a common approach in the insurance industry. A variation of this downside risk perspective considers failure to reach upside potentials as equally important and interprets this as an opportunity cost. Risk can also be conceived as the difference between expectations and actual outcomes thus seeing risk more as uncertainty. Hence, we can define a risk factor as an environmental condition that gives rise to a risk exposure, i.e., the chance that 
some identifiable scenario may occur and inflict economic damage or impose opportunity cost on the corporation. The most commonly recognized risk factors relate to changes in financial market prices. Textbooks on multinational financial management typically relate risk exposures to earnings effects associated with changes in future foreign exchange rates [1,2]. The currency exposures arise when there is a mismatch between foreign exchange rate denominated receivables and payables over time that make the value conversion into the currency of accounting uncertain [3]. The field distinguishes between accounting exposures that translate currency denominated assets and liabilities in the financial statements and future cash flow effects of financial and commercial activities denominated in foreign currencies. Transaction exposures derive from contractual obligations denominated in foreign currencies and operating exposures relate to future effects on cash flows as changes in foreign exchange rates affect demand conditions, international price developments, etc. Together transaction and operating exposures are referred to as economic exposures comprising all future cash flow implications deriving from changes in foreign exchange rates. Most registered transactions are relatively short-term in nature, such as booked trade transactions but could also include medium-term payments associated with debt obligations, etc. Operational exposures, on the other hand typically relate to estimates of future longer-term not yet booked commercial activities.

Interest rate exposures arise when there is a mismatch between the re-pricing dates of assets and liabilities [3]. A corporation may generate cash from its current operations and obtain additional financing through bank loans and securities issuance to fund different investment opportunities identified around the world. In these cases the expected timing of future cash flows and the rate bases associated with the funding instruments differ and hence constitute potential interest rate exposures. In principle these interest rate gaps exist in all currencies in which the organization has engagements and the gap analysis ought to be performed for each currency area. Duration measures provide the means to determine overall sensitivities to changing market conditions as reflected in the interest rate level. The duration of the corporate equity position equals the duration of assets minus the duration of liabilities and the effect on the market value of the equity position $(\Delta \mathrm{E})$ for a given change in the interest rate $(\mathrm{r})$ can be determined as $\Delta \mathrm{E}=-\left(\mathrm{D}_{\mathrm{A}}-\mathrm{L} / \mathrm{A}^{\mathrm{x}} \mathrm{D}_{\mathrm{L}}\right) /(1+\mathrm{r})^{\mathrm{x}}$ $\mathrm{A}^{\mathrm{x}} \Delta \mathrm{r}[4]^{1}$. This implies that it is possible to extend duration analysis to comprise all material assets and liabilities on the corporate balance sheet. The only condition is that it is possible to stipulate the future cash flows that characterize the assets and liabilities and determine their indicative market values. In a multinational enterprise, equity duration gaps should be considered for each of the currency areas in which it operates. A simple way to assess the overall enterprise exposure is to aggregate the value effects of the duration gaps across the currencies at prevailing foreign exchange rates and compare the aggregate effects to net income and total equity to determine whether the exposure is reasonable.

\footnotetext{
${ }^{1} \mathrm{D}_{\mathrm{A}}$ indicates the duration of total assets, $\mathrm{L}$ is the market value of total liabilities, $\mathrm{A}$ is the market value of total assets, $\mathrm{D}_{\mathrm{L}}$ is the duration of total liabilities, $\mathrm{r}$ is the current interest rate level, and $\Delta \mathrm{r}$ indicates the percentage point change in the interest rate level.
} 
Corporations engaged in international transactions are exposed to different financial and market related risk factors caused by changes in foreign exchange rates, interest rate rates, securities prices, commodity prices, etc. However, corporations can be exposed to many other important risk factors and there is a wide range of factors to consider beyond the relatively narrow scope of financial risks. We may use a systematic risk classification to consider different risk factors. One risk classification scheme separates risks into general environmental risks, industry related risks, and company related risk [5]. The idea behind this framework is to first analyze general environmental conditions and then gradually narrow the scope to focus on more firm specific issues (Figure 1). Environmental risks comprise factors that characterize the physical context for global business operations and trends in the overall socio-economic system including influences from natural phenomena, man-made disasters, and terrorist events. Socio-economic developments comprise evolving political sentiments, macroeconomic conditions, regulatory intervention, etc. Industry related risks influence the competitive situation of the specific industrial context in which the corporation operates. This comprises elements that are peculiar to the industry, such as, changing customer needs, actions of close competitors, technological innovations, etc. Company related risks relate to internal conditions prevailing within the organization itself as they are manifested, e.g., through the way work is organized, people are motivated, decision are made, actions controlled, and so forth and include operational risk, documentation risk, and commercial risk. The more we move towards these types of risk, the more difficult it becomes to measure the associated exposures as return deviations and risk elements emerge more like uncertainty. Nonetheless, these risk factors can be highly significant and consequently must be dealt with in the risk management process.

- please insert Figure 1 about here -

An alternative way to assess the potential simultaneous impact of multiple risk factors is captured by the notion of value-at-risk ( $\mathrm{VaR}$ ) initially developed to obtain a single measure of the aggregate exposure of many market related risks. VaR indicates the expected value outcome (loss) over a certain time period at a given probability level $(\alpha)$, i.e., there is a likelihood of $\alpha$ percent that the loss will exceed VaR during the time period. VaR can be determined on the basis of historical variance-covariance relationships between the market value of assets and liabilities. If the prices reflect daily price quotes or value indications, the change in market value corresponds to daily risk exposures although other time periods might be relevant to consider as well ${ }^{2}$. The variance-covariance relationships between the market values of different international assets and liabilities measured in the local currency of accounting comprise both interest rate fluctuations in the

\footnotetext{
${ }^{2}$ Risk measures based of the standard deviation in the daily price quotes can be converted into comparable measures for alternative time periods, e.g., $\sigma_{\text {month }}=\sigma_{\text {day }}{ }^{x}(21)^{1 / 2}$, assuming 21 valuation days in a month corresponding to 252 trading days per year.
} 
currency areas as well as concurrent changes in the foreign exchange rates. Hence, the resulting local currency based risk measures incorporate both interest rate and currency risks as well as other price effects deriving from changing business conditions, such as changes in default risk, market liquidity, etc. The valueat-risk concept depends on the chosen level of statistical significance as a lower level of significance corresponds to a higher value-at-risk, i.e., a lower confidence level captures a more conservative risk perception. Ninety percent of all observations in a normal distribution fall within a range spanning from $1.645 \sigma$ to $+1.645 \sigma(\sigma=$ standard deviation, factor $=1.645)$. Hence, the lower range indicator determines the outcome that reflects a 5\% likelihood of occurring. Conversely, $98 \%$ of all observations in a normal distribution fall within $-2.326 \sigma$ and $+2.326 \sigma$, i.e., the lower indicator determines the outcome with a $1 \%$ probability. Once the standard deviation of the value outcomes of a portfolio or an equity position is determined and the level of significance chosen, the value-at-risk can be determined as $\mathrm{VaR}=\mathrm{Current}$ market value ${ }^{\mathrm{x}}$ factor ${ }^{\mathrm{x}}$ standard deviation [4]. This illustrates how it is possible to quantify an aggregate risk exposure and develop a measure of a potential downside value loss associated with a given business portfolio or equity position.

Other risk exposures caused by the failure of human and technological interactions in organizations, including mistakes, fraud, computer breakdowns, etc., have received increased recognition. Country, sovereign, and political risk factors are related to default risk but constitute additional concerns associated with cross-border transactions and global operations as the corporation gets exposed to political, economic, and legal systems outside the home country jurisdiction. Smaller casualty risks associated with accidents and the like are typically covered on the basis of comprehensive insurance policies. As long as the risk events are independent of each other, the underlying exposures are diversifiable across larger insurance portfolios and the premiums can be determined probabilistically. Hence, large enterprises with substantial casualty exposures may as well self-insure these risks possibly through the establishment of captive insurance companies. If primary insurers or corporations have accumulated large exposures within similar types of insurance risk they may cede part of their exposures to global reinsurance companies and the reinsurance companies may in turn retrocede part of their exposures to other reinsurance companies to diversify the risk across the international insurance market. However, catastrophe risks represent extreme loss potentials and by definition are not independent since losses are highly correlated within geographical areas. Therefore, catastrophe exposures are typically ceded in the reinsurance market as facultative treaties covering specific risk factors. The reinsurance market typically deals in insurance layers where losses in excess of a deductible are covered up to a maximum amount, the exhaustion point.

The catastrophe events may relate to extreme natural phenomena and involuntary man-made disasters as well as terrorist incidents. A systematic assessment of these risks builds on preliminary analyses of the exposures. 
For example, reviews of historical loss records provide valuable background information to describe major hazards, such as, floods, windstorms, earthquakes, etc., and the direct economic impact of identified hazards can be determined from extensive computerized simulations or simpler scenario analyses. The resulting exposure profiles can be used to assess possible mitigation efforts and alternative risk-transfer and financing programs to cover residual exposures. The direct economic impact of disaster events may be determined from simulation models based on information about potential hazard intensities, listings of exposed economic assets, their vulnerability to the hazards, and the expected replacement cost of damaged assets [6]. A set of stochastic occurrence parameters describing possible hazard events can be used to perform Monte Carlo simulations that describe the likely economic effect of the hazard events. The direct economic loss can then be found by multiplying the asset inventory list with the average cost of each asset type ${ }^{3}$. In the case of terrorism related events it is important to consider changing event patterns that evolve dynamically. Potential terrorist incidents are driven by human ingenuity and are, therefore, difficult to predict although they can be countervailed through foresight. Based on assumptions about possible terrorist hazards and predictions on their frequencies and intensities vulnerability models can transpose these assumptions into simulated loss estimates. Many strategic risks may employ comparable assessment techniques but are in some cases harder to identify, quantify, and assess. The handling of relatively rare disaster events is a major caveat in risk management because they are difficult to forecast. Disaster events could also relate to financial risks, e.g., when price structures change abruptly in completely unexpected ways or business confidence collapses as witnessed occasionally in the global stock market. They could relate to political crisis such as sovereign default events, mounting military actions, and civil unrest. They may also relate to major technology shifts or extreme disaster scenarios of different kinds. The potential effects from natural and man-made disasters as well as terrorism events can be assessed through the use of simulated risk scenarios, risk intensity patterns, and identified asset vulnerabilities.

The multinational enterprise can only assume a certain level of risk retention across different risk categories and will employ various financial hedging, risk-transfer, and management techniques to cope with excessive exposures. The higher-level financial risks are relatively easy to cover in the derivatives markets for short to medium-term time periods. Casualty risks may be covered through general policies obtained in the insurance market often arranged as multi-line insurance policies. Higher risk layers related to specific hazards may be ceded in the reinsurance market on an excess-of-loss basis possible through issuance of risk-linked securities. For harder to quantify risk exposures hedging and risk-transfer may not be a viable route but could be covered through general committed credit facilities and contingent capital instruments (Figure 2).

\footnotetext{
${ }^{3}$ The calculation of the direct economic risk exposure (DER) can be formalized as DER $=\mathrm{p}^{\mathrm{x}} \mathrm{v}^{\mathrm{x}} \mathrm{h}{ }^{\mathrm{x}}$ ICL, where $\mathrm{p}=$ probability of the hazard event, $\mathrm{v}=$ vulnerability factor of capital asset, $\mathrm{h}=$ hazard intensity factor, and $\mathrm{ICL}=\mathrm{insured}$ capital loss or value at risk.
} 
- please insert Figure 2 about here -

However, there is a limit to the available risk-transfer instruments for very firm specific exposures. Therefore, corporate management should consider natural internal hedges that may reduce these risk exposures. For example, in the case of long-term movements in foreign exchange rates the associated economic exposures might be reduced if production facilities are distributed across major currency areas. If globally distributed manufacturing plants represent operational flexibility it might even be possible to exploit favorable currency trends by shifting production volume between currency areas [7]. This constitutes real option structures based on corporate asset configurations and the establishment of relevant options-related flexibilities could prove tremendously valuable, for example, by establishing flexible sourcing channels that allows for periodic shifts in factor supplies from different currency areas, etc. [8, 9].

\section{Arguments for hedging}

Corporations that ignore potential risk factors are hit harder when adverse events happen because they do not expect the events and insufficient precautions are taken in advance. When potentially adverse events are recognized before they happen and potential causes behind such events analyzed, the element of uncertainty is vastly reduced [11]. It is argued that hedging should be pursued to ensure available cash for sound investment propositions. If an institution with a given funding base is exposed to excessive risks, there is not sufficient cash available for positive net present value projects, because the inherent bankruptcy risk requires a larger financial buffer. This so-called under investment problem reduces the ability to optimize the economic potential of the institution in the absence of risk management [12]. To the extent that earnings volatility is reduced it will arguably lead to lower average cost of capital, which should expand the number of viable business opportunities available to the corporation. It is further argued that hedging should be pursued to the extent that it stabilizes relationships to essential stakeholders. A number of stakeholder groups such as employees, customers, and partners establish idiosyncratic structural relationships to work closely with the corporation and may not be able to readily trade and restructure these positions [13]. Hence, the corporation may have a vested interest not to jeopardize these intricate relationships by maintaining an erratic earnings development. This means that hedging should be pursued to ensure that financial resources remain available at reasonable costs and that important commercial relationships are retained even when the firm is exposed to unexpected and unforeseeable events. A recent comparable perspective argues that hedging and risk management efforts can help reduce uncertainty and thereby improve conditions for engaging in firm specific investment that can provide the basis for improved economic performance and excess returns [14]. 
Risk management formally starts with the identification of significant risk factors that might cause business disruption, create new business opportunities, and expose the value of corporate assets and liabilities [15]. Then the vulnerability to the identified risks, including financial market factors, socio-economic developments, competitive moves, natural disasters, terrorist acts, etc., are analyzed. Measures of potential adverse value effects can provide a basis to assess the effectiveness of risk mitigation efforts and benefits from hedging through engagement in derivative instruments, insurance contracts, risk financing, etc. This risk measurement framework is used to monitor developments in economic exposures and assess changes in the risk environment that may require new responsive actions and a reassessment of contemporary risk factors (Figure 3). The entire risk management approach should be conceived as an ongoing process. Since environmental conditions continue to change, the profile of the institution's risk exposures is likely to change dynamically and, therefore, should be updated on a regular basis.

- please insert Figure 3 about here -

Many financial exposures can be covered by trading in financial futures, options, and various over-thecounter derivatives including forward rate agreements, currency and interest rate swaps, credit default swaps, etc. This kind of hedging can lock-in future prices and shield against market volatility for intermediate time intervals, say within the accounting year and in some cases even longer. This kind of hedging can fix future price relationships at prevailing futures and options prices that reflect general market expectations. However, for a corporation to gain abnormal returns it must take a view on future price developments that differs from other market participants, and be right about it. The fixing of future price levels through engagement in financial derivatives can diminish unpleasant fluctuations in corporate earnings but in dynamic business environments, corporations are exposed to other factors that are beyond the transparency of traded markets. Many risk factors are idiosyncratic to the individual corporation and its specific resource endowment and consequently cannot be covered through use of derivatives and conventional hedging techniques but require other risk management approaches, such as, real options reasoning and responsive behaviours.

\section{Casualty, catastrophe, and terrorism risk}

A central feature of catastrophe risk exposure is that the insurance premiums associated with these events are sensitive to the uncertainty surrounding the loss calculations of hazard exposures. Hence, it is noted that the 
relative price of insurance increases exponentially for higher risk layers [16]. This is so because it is comparatively easier to predict higher frequency events in lower risk layers than infrequent events in higher risk layers where the level of uncertainty can be extreme. Whereas these observations apply to all types of catastrophe risks, the uncertainty element is more pronounced in the case of natural phenomena and terrorist incidents. Since terrorist events are caused by willful human actions, the catastrophe events do not necessarily follow common routines or patterns but change character as terrorists try to adapt to changing conditions. This human element is peculiar to terrorism risk and makes it difficult to use historical event data for actuarial loss estimations. The focus of terrorist activities may converge toward more remote and less protected geographical regions where terrorists may target economic or symbolic facilities. This would predict a future pattern of smaller but more frequent events across many geographical regions. Multinational enterprises are often exposed to such risks and need to take precautions against threats to overseas facilities and personnel. On the other hand, the geographic dispersion of productive assets, human resources, and business activities also helps diversify the exposures.

Terrorist events may also diverge from more conventional uses of explosives towards suicide bombings, smaller missile based attacks, etc., all of which have happened in different parts of the world. Whereas these forms of terrorism entail smaller direct economic exposures, they have potential secondary economic effects to the extent they are able to break business confidence and affect public morale. Other possible means of terrorism might be aimed towards extreme uses of nuclear, biotechnological, and chemical (NBC) agents. This requires a higher level of technical skill, which makes the occurrence less likely at least in the near term. However, the uncertainty associated with the economic effects of these types of events is high. Consequently, mega-terrorist acts may be less likely to occur while smaller incidents could happen more frequently across different geographical regions. In the case of relatively well-defined small to medium sized terrorism exposures, there is a reasonable chance that, e.g., reinsurance contracts, risk-linked securities, and cat-bonds can be tailored to deal with these risks [17]. Recent examples of alternative risk-transfer solutions to terrorist exposures is FIFA's cover for cancellation of the 2006 World Cup and the Swiss Re sponsored Vita Capital cover for excess mortality risk. FIFA obtained cover through risk-linked securities issued by a special purpose vehicle, Golden Goal Finance Ltd., created to securitize FIFA's expected revenues from the World Cup arrangement and secure repayment of prepaid amounts in case of cancellation, abandonment, or curtailment of the scheduled World Cup arrangement. The relevant risk-transfer instruments to consider in relation to catastrophe and terrorism events include reinsurance contracts, risk-linked securities, contingent capital, and committed credit facilities. The reinsurance market for catastrophe risk is well developed, but market conditions are influenced by recent loss experiences and premiums for higher risk layers can become excessively expensive. However, the emergence of new risk securitization techniques provides additional risk-transfer capacity in the capital market. 


\section{Competitive and strategic risks}

Adopting a real options perspective can facilitate the identification of firm specific flexibilities that increase the corporation's ability to avoid downside risk and exploit upside business potential. It can also provide an analytical framework to support resource-committing decisions under uncertainty. It has been argued that flexible manufacturing facilities located in major currency areas constitute options to switch production across the most cost effective locations in the multinational network. Derivative instruments provide multiple risk-transfer opportunities for all conceivable market risks whereas the introduction of real options provides a new perspective to handle firm specific economic and strategic exposures. The real options perspective was initially inspired by the identification of growth options in conjunction with capital budgeting exercises. There was a realization that conventional investment analysis ignored potential follow-up investments as projects could develop competencies to support future strategic initiatives. Investing to gain knowledge about new markets and subsequent entry into them can create growth options that allow the corporation to enter other related markets at later points in time. Initial investment in new business activities can also allow the corporation to exit and re-enter related markets as conditions change. The discounted cash flow methodology adopted to calculate project values usually conceived investment alternatives as predetermined paths implying either-or investment decisions, which ignores incremental value associated with flexibilities related to the structure and timing of investments as well as alternative uses of assets.

Asset flexibility and the ability to re-deploy corporate resources in the face new competitive conditions are essential features of effective risk management. Real options represent business opportunities that are distinct from financial options by their dependence on idiosyncratic resources in the corporation. The market price of the underlying asset corresponds to the investment value of the project and the strike price of the real option corresponds to the required initial project investment. Hence, a real option structure constitutes a right, but not an obligation, to carry out particular actions at some future point in time [18] and represent incremental value to the corporation because they can be exercised under favourable conditions and left alone if conditions are unfavourable. The real option structures are bounded by real market flexibilities associated with the corporation's input and output procurement (Figure 4).

- please insert Figure 4 about here -

The real option structures are shaped by corporate resources and capabilities including assets, processes, and intellectual capital. Option structures can, for example, provide opportunities to implement new technologies and procedures, offer new products and services, approach new customer segments, geographical markets, 
etc. A multinational enterprise has access to many diverse resources that provide a strong base for potential real option structures. The real options can be conceived as strategic opportunities that establish unique choices between alternative actions and thereby allow the corporation to change market position. Since the choice to exploit these opportunities is under discretionary corporate control. Some strategic opportunities are framed already within the firm's existing resource-base and constitute so-called latent options that are waiting to be discovered. Hence, it is necessary to recognize the existence of particular option structures and potential business opportunities before they can be developed and eventually utilized. Strategic opportunities are firm specific and the uncertainty that circumscribe them depends on the level of collective environmental insight residing among managers and key individuals in the corporation. The utilization of identified option structures for risk management purposes is, therefore, dependent on an effective corporate strategy process where involvement and communication among organizational members can improve market insights and support the options exercise decisions.

\section{$4 \quad$ An integrative strategic risk perspective}

In the past, many risks were handled by different corporate functions but this approach disregards interactions between the risk factors. Instead management should identify the essential risks, assess the associated exposures, and determine how the corporation should manage the exposures through hedging, risk-transfer, and real option structures within a tolerable risk profile. To assess all the potential risks that expose the corporation, senior management should perform a comprehensive risk review of all businesses entities focused on the conditions that permeate their external environment as well as internal organizational traits including productive assets, operational infrastructure, processes, human resources, etc. Such a focused review can help identify risk factors that may inhibit the ability to achieve longer-term corporate objectives. The identification of essential risk factors creates awareness around important environmental changes that could affect corporate performance and could be used to develop responsive actions. Some risk factors may not require immediate responses but are nonetheless brought to the attention of management for ongoing consideration. In many ways, this is exactly what is supposed to take place in a formal strategic management process, which embraces risk assessment as an integral part of the environmental analyses. This is consistent with a risk management processes attempting to identify, monitor, and manage essential risk factors. The analytical exercises in the strategic planning process may result in the completion of action plans aimed to reach superior strategic positions and contingencies responding to potential changes. While this can prove insufficient under extremely turbulent conditions, the analytical considerations should prepare decision makers for unexpected events while supporting general risk awareness (Figure 5). Formalized risk control 
systems can monitor identified risk factors and initiate responses to mounting exposures akin to the strategic control system exemplified in balanced scorecards and the like [19].

- please insert Figure 5 about here -

Conventional views on multinational corporate exposures primarily consider the impact from variations in foreign exchange markets and longer-term effects from changing macroeconomic conditions. In this context, it is important to consider interrelationships between financial and economic risk factors and not just assess the short-term foreign exchange market risks in isolation. Over time changes in foreign exchange rates are related to comparable moves in interest rate structures between currency areas as well as differences in demand conditions, commercial default rates, and inflationary expectations across national economies. Similarly, input supply, product demand, and competitive risk factors can be related to fluctuations in real exchange rates. In other words, different types of financial and economic risk exposures are often interrelated [20]. Therefore, it is important to consider interactions across the full range of risk factors that may affect future corporate performance including political, economic, competitive, and technological risks. The interrelatedness may also extend across other types of risk, such as, natural hazards, man-made disasters, and terrorist events as they affect macroeconomic and financial market variables. Therefore, the challenge is to consider all the relevant risk factors rather than adopting simple one-to-one mapping of risk exposures. Accordingly, hedging practices should consider the entire corporate exposure profile and deal with the risk factors in an integrative manner.

The assessment of risk effects on future corporate cash flows is typically performed across different time horizons. Conventional analyses of potential effects from financial market volatilities is typically performed within a near term perspective covering rather short-term accounting exposures. However, the more uncertain and less quantifiable medium to longer-term exposures, including geopolitical and competitive risks as well as natural hazards and terrorist events can be equally, if not more important. Whereas this is generally recognized among corporate managers, it is rarely addressed in practice due to the ambiguity involved in the handling of hard-to-quantify uncertainties. The significance of medium and longer-term exposures of, say political, competitive, and technology risks is further accentuated by the changing nature of the external business environment where disruptive hypercompetition is the order of the day [21]. In many cases the true risk factors cannot even be known in advance and may arise without prior warning. Such factors can also include operational risks where corporations are exposed to a number of internal vulnerabilities related to process quality, control systems, etc. From a risk management perspective both 
external and internal risk factors are important and should be considered as the hallmark of a systematic strategic management process.

\section{Discussion}

It is possible to use different derivative instruments to hedge and adjust financial and market related exposures but it might not always be a viable route. For example, it is not be reasonable to use short-term interest rate futures and medium-term interest rate swaps to modify the duration gap of a corporate equity position, which reflects value effects on long-term assets and liabilities. In such cases, it is more appropriate to modify the maturity structure of the assets and liabilities themselves, i.e., if the duration gap is considered excessive it makes sense to reduce financial leverage and modify engagement in business projects with distant prospective revenue streams. In other words, traded derivative instruments are meaningful tools to modify short to medium-term financial exposures but if these exposures relate to longer-term economic risks, the corporation may need to adjust the underlying business and funding strategies. For example, in situations where a central foreign exchange rate seems to be developing in time cycles that exceed the maturities offered in the derivatives markets other hedging approaches are required to do the job. The development in the euro-dollar foreign exchange rate over the past decade displays such a situation. Hence, a number of European based exporters with significant sales in the US market felt the heat during 2004 as the value of their dollar receivables dropped. The European corporations that fared best during this period were companies with overseas US manufacturing facilities and, therefore, could take advantage of a weaker dollar to reduce the cost base.

Rapid-onset high-impact catastrophe risks such as natural disasters, man-made disasters, and terrorist events are difficult to describe precisely and the associated risk-transfer solutions constitute a challenge to the risk management practice. A multinational enterprise that has dispersed activities throughout the globe by the same token achieves a degree of risk diversification because natural phenomena and terrorist actions rarely are correlated across geographical locations. Nonetheless, to the extent significant productive corporate resources are concentrated in specific exposed regions there is a need to mitigate and cover the exposures. Reasonably diversified risks may be covered through comprehensive global insurance policies or could be self-insured by the corporation. The large location specific exposures may be covered through facultative excess-of-loss reinsurance contracts or could be prone to coverage through issuance of risk-linked instruments in the global capital market. However, these risk-transfer solutions are still under development and constitute an interesting potential in corporate risk management considerations. 
Other exposures are firm specific particularly with respect to operational and competitive risks that depend on corporate resources and the ability to deploy them in effective responsive actions. As a consequence, these risk factors and the responses to them must be considered and managed in view of the specific industry and corporate environment. Hence, the identification of essential risks factors will differ from one organization to another partly because business portfolios rarely are perfectly comparable and because risk perceptions are influenced by knowledge imbedded in the organization. The effective handling of emerging risks and unexpected competitive situations depends on the ability to sense environmental change and mobilize internal resources in appropriate and timely responses. In this context, the identification and creation of real options can help for the corporation's ability to establish operational flexibilities and exploit strategic opportunities but it is not a sufficient condition for superior performance. It is equally important to devise internal processes that allow the corporation to improve the execution of strategic opportunities that can result in superior returns [18]. Hence, an important step towards more effective strategic risk management practices is to recognize that firms must be able create relevant real option structures as well as effectively exploit them under conditions of environmental turbulence.

The foundation for effective strategic risk management lies in top management's imposition of an internal risk awareness culture and the monitoring of essential risk exposures. To furnish corporate responsiveness it is necessary to instil a managerial mindset that is sensitive to new environmental developments, display openness to change, and a willingness to challenge prevailing mental models [22]. The corporation should maintain an organizational structure that facilitates change and adaptive responses when significant environmental changes occur. Whereas the integrative perspective is primarily imposed on a formal planning framework it also depends on more complex informal process that takes place across organizational entities. Organizations that are able to effectively coordinate work tasks across flexible networks of functional entities and individual specialists have a better chance to interpret information about environmental change and convert it into relevant responsive actions. These networks are supported by informal communication capabilities and can be enhanced by use of advanced information technologies. Open communication channels among managers throughout the organization reduce information distortion and enable coordination of organizational tasks. Richer and more detailed information can be processed because it is registered and exchanged closer to the original sources without major distortions. The fact that the information can be exchanged, reviewed, and commented by managers from different functional areas can facilitate the interpretive process of the information and lead to better responses. 
Instituting a general awareness about environmental risk factors is a way to sharpen an organization's ability to manage risk exposures more effectively. To the extent management can engage and train key people across the organization to observe the changing environment and ponder about the possible consequences for the corporation the higher the likelihood that the organization will be able to respond to turbulent conditions in a timely manner. The engagement in formal risk assessment exercises can provide a better understanding of corporate exposures and enhance general risk awareness but obviously does not constitute a universal provision to avoid unfortunate consequences of exogenous events. The fact that some of the major components in contemporary risk scenarios are determined by elements that cannot be known in advance such as technological innovation, competitor moves, natural hazards, man-made disasters, and terrorist events accentuates this point. While formal risk management can sharpen recognition around identified risk factors it is equally important to establish a corporate ability to sense and react to hitherto unknown environmental threats and opportunities. 


\section{References}

1 Eiteman, D. K., Stonehill, A. I., Moffett, M. H. (2004), Multinational Business Finance (10 ${ }^{\text {th }}$ ed.), Pearson Addison-Wesley.

2 Shapiro, A. C. (2003), Multinational Financial Management $\left(7^{\text {th }}\right.$ ed.), Wiley.

3 Saunders, A. and Cornett, M. M. (2003), Financial Institutions Management: A Risk Management Approach ( $4^{\text {th }}$ ed.), McGraw-Hill Irwin.

4 Andersen, T. J. (1993), Currency and Interest Rate Hedging (2 $2^{\text {nd }}$ ed.), Prentice-Hall.

5 Miller, K. D. and Waller, H. G. (2003), ' Scenarios, Real Options and Integrated Risk Management', Long Range Planning, 36.

6 Andersen, T. J. (2004), 'Managing Economic Exposures of Natural Disasters', Special Report, InterAmerican Development Bank.

7 Kogut, B. (1985), 'Designing Global Strategies: Profiting from Operating Flexibility', Sloan Management Review, Fall.

8 Bowman, E.H. and Hurry, D. (1993), 'Strategy Through the Options Lens: An Integrated View of Resource investments and the Incremental-Choice Process, Academy of Management Review, 18.

9 Kogut, B. and Kulatilaka, N. (1994), 'Operating flexibility, global manufacturing, and Option Value of a Multinational Network', Management Science, 40.

10 Tang, C. Y. and Tikoo, S. (1999), 'Operational Flexibility and Market Valuation of Earnings', Strategic Management Journal, 20.

11 Bernstein, P. L. (1996), Against the Gods: The Remarkable Story of Risk, Wiley.

12 Froot, K. A., Scharfstein, D. S. and Stein, J. C. (1994), 'A Framework for Risk Management', Harvard Business Review.

13 Miller, K. D. (1998), 'Economic Exposure and Integrated Risk Management', Strategic Management Journal, 19.

14 Wang, H., Barney, J. B. and Reuer, J. J. (2003), 'Stimulating Firm-Specific Investment through Risk Management', Long Range Planning, 36.

15 Culp, C. L. (2002), The ART of Risk Management, Wiley.

16 Pollner, J. D. (2001), 'Managing Catastrophic Disaster Risks Using Alternative Risk Financing and Pooled Insurance Structures', Technical Paper, The World Bank.

17 Andersen, T. J. (2004), ,International Risk Transfer and Financing Solutions for Catastrophe Exposures', Financial Market Trends, 87, OECD.

18 Andersen, T. J. (2000), 'Real Options Analysis in Strategic Decision Making: An Applied Approach in a Dual Options Framework', Journal of Applied Management Studies, 9(2).

19 Simons, R. (2000), Performance Measurement \& Control Systems for Implementing Strategy, Prentice Hall.

20 Oxelheim, L. and Wihlborg, C. G. (1987), Macroeconomic Uncertainty: International Risks and Opportunities for the Corporation, Wiley.

21 D’Aveni, R. (1994), Hypercompetition, Free Press.

22 Bettis, R. and Prahalad, C. K. (1995), 'The Dominant Logic: Retrospective and Extension', Strategic Management Journal, 16. 


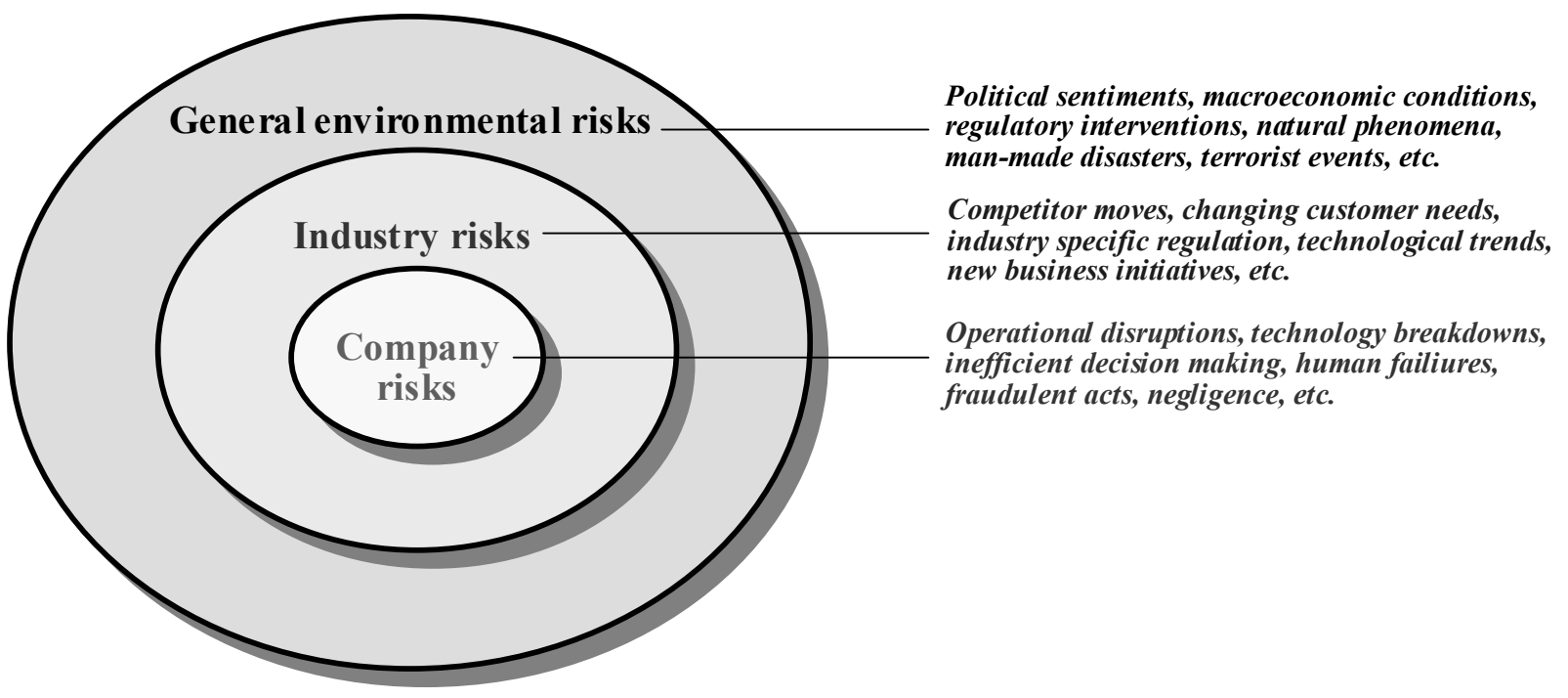




\section{Figure 2 A Corporate Risk-Transfer and Financing Structure}

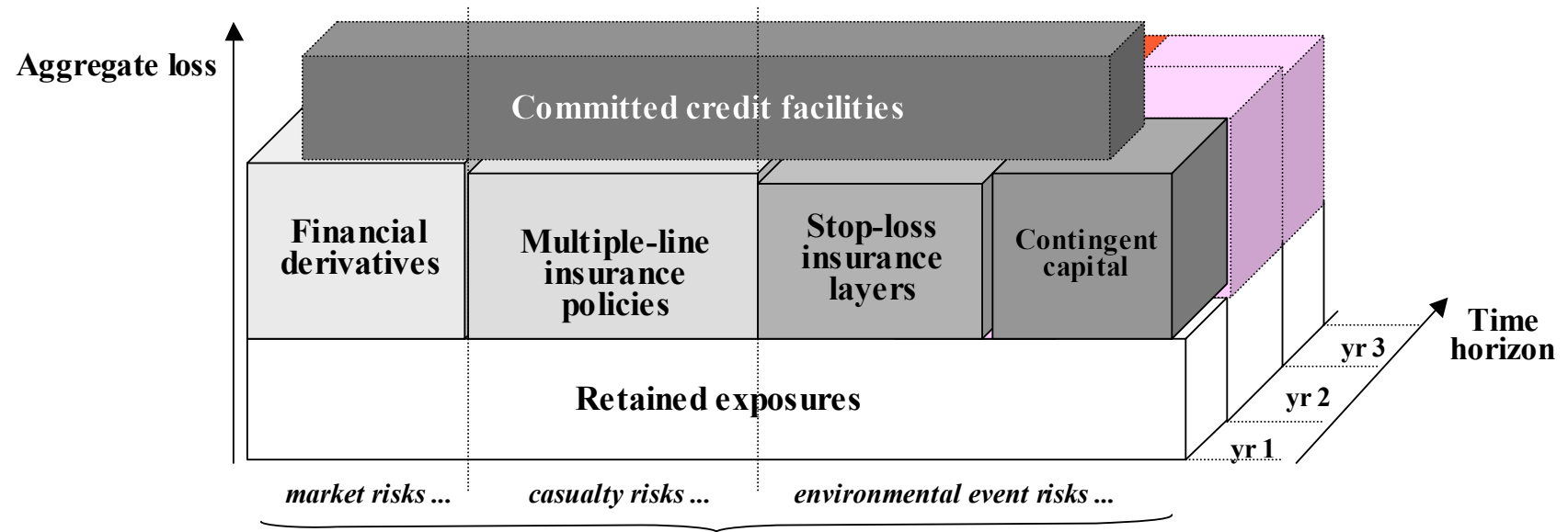

Risk factors 
Figure 3 A Formalized Risk Management Process

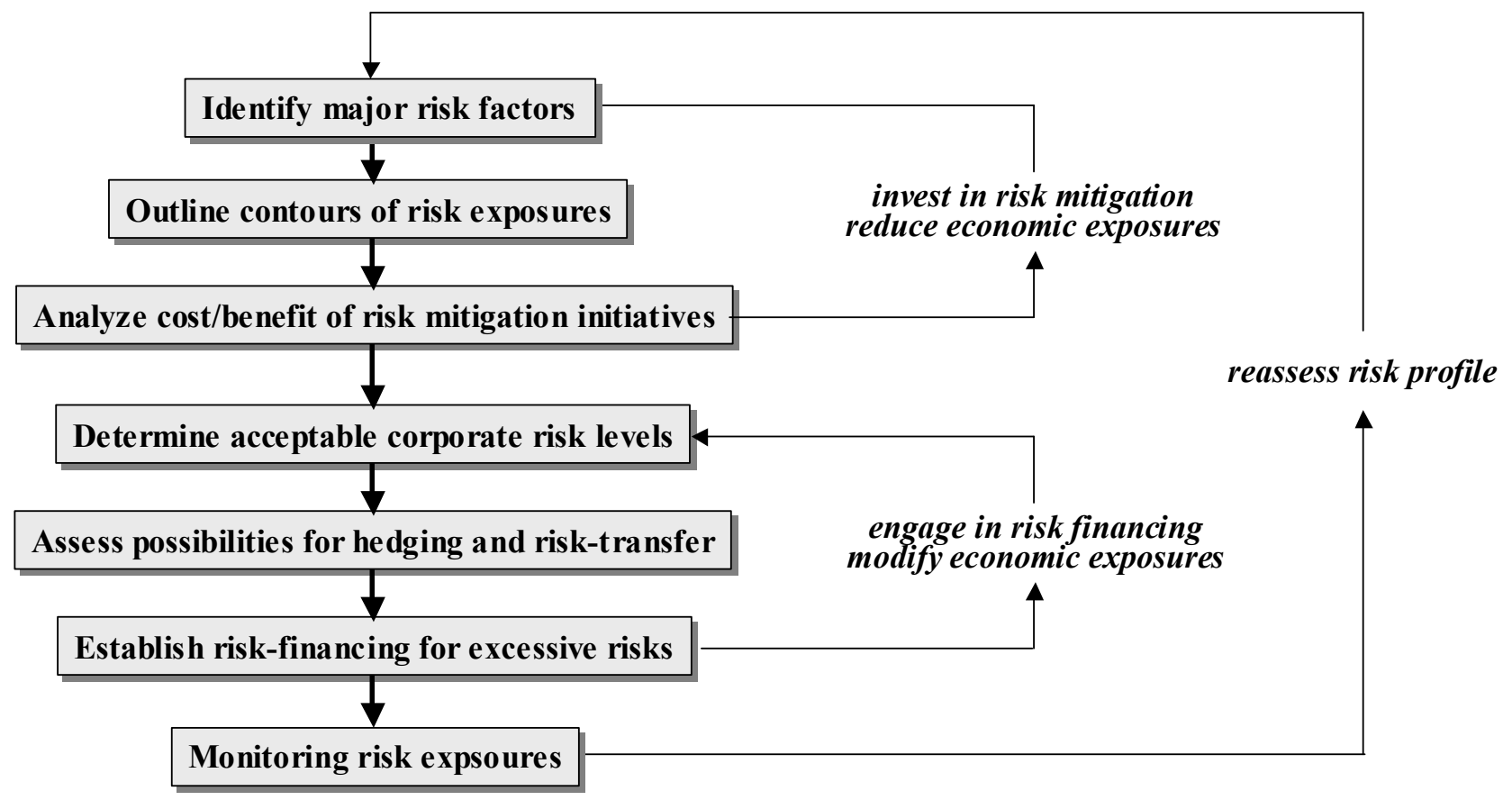


Figure 4 Financial and Real Market Flexibilities

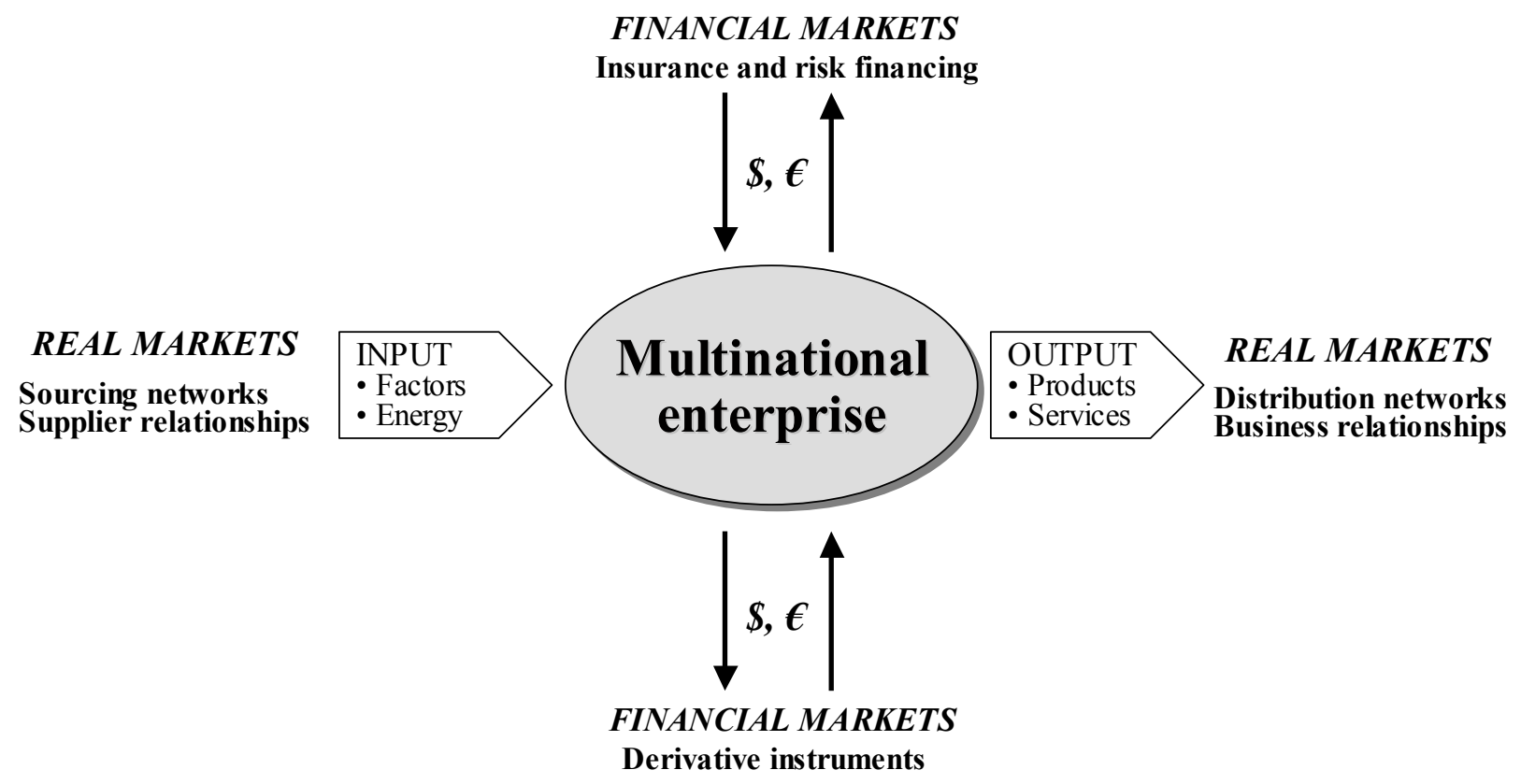


Figure 5 The Strategic Risk Management Process

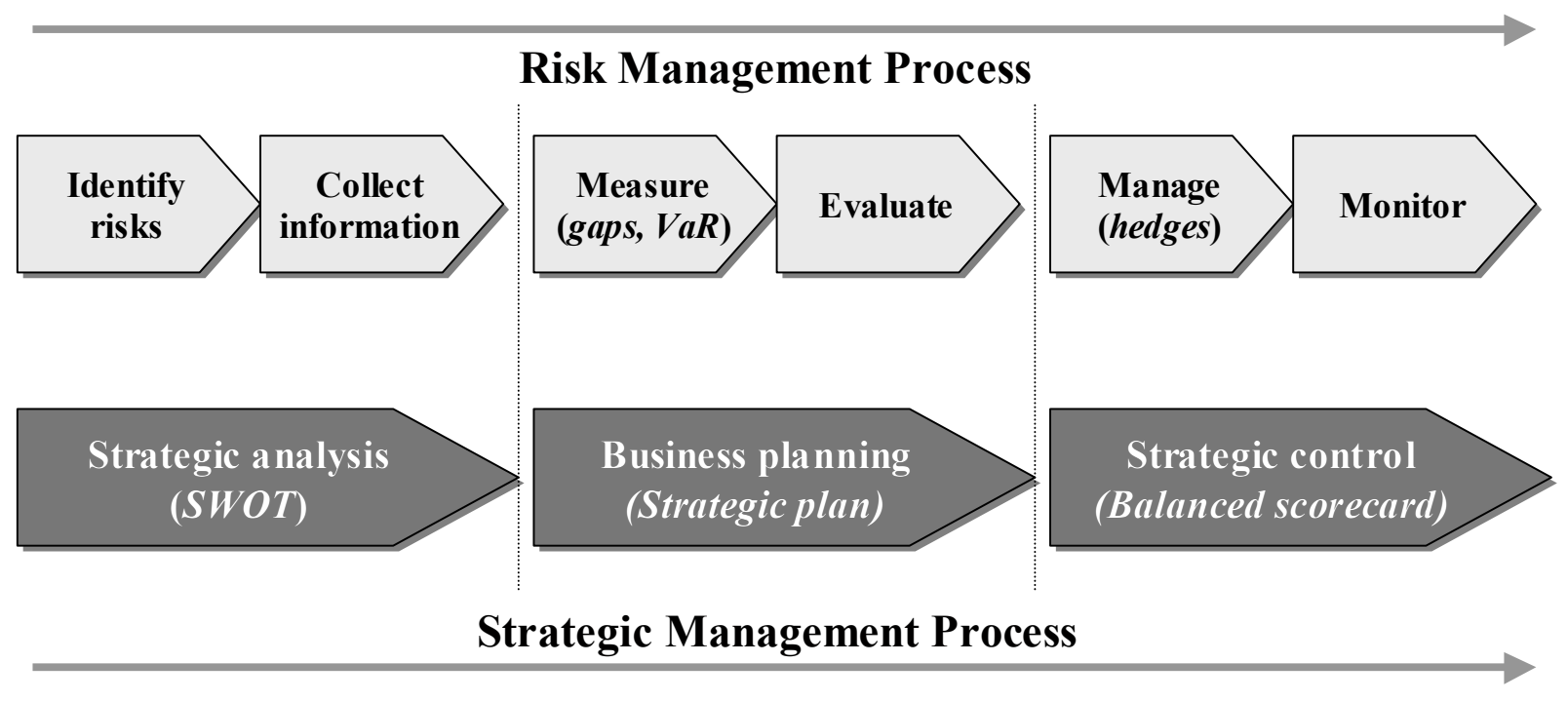




\section{SMG - Working Papers \\ www.cbs.dk/smg \\ 2003}

2003-1: Nicolai J. Foss, Kenneth Husted, Snejina Michailova, and Torben Pedersen: Governing Knowledge Processes: Theoretical Foundations and Research Opportunities.

2003-2: Yves Doz, Nicolai J. Foss, Stefanie Lenway, Marjorie Lyles, Silvia Massini, Thomas P. Murtha and Torben Pedersen: Future Frontiers in International Management Research: Innovation, Knowledge Creation, and Change in Multinational Companies.

2003-3: Snejina Michailova and Kate Hutchings: The Impact of In-Groups and OutGroups on Knowledge Sharing in Russia and China CKG Working Paper.

2003-4: Nicolai J. Foss and Torben Pedersen : The MNC as a Knowledge Structure: The Roles of Knowledge Sources and Organizational Instruments in MNC Knowledge Management CKG Working Paper.

2003-5: Kirsten Foss, Nicolai J. Foss and Xosé H. Vázquez-Vicente: “Tying the Manager's Hands": How Firms Can Make Credible Commitments That Make Opportunistic Managerial Intervention Less Likely CKG Working Paper.

2003-6: Marjorie Lyles, Torben Pedersen and Bent Petersen: Knowledge Gaps: The Case of Knowledge about Foreign Entry.

2003-7: Kirsten Foss and Nicolai J. Foss: The Limits to Designed Orders: Authority under "Distributed Knowledge" CKG Working Paper.

2003-8: Jens Gammelgaard and Torben Pedersen: Internal versus External Knowledge Sourcing of Subsidiaries - An Organizational Trade-Off.

2003-9: Kate Hutchings and Snejina Michailova: Facilitating Knowledge Sharing in Russian and Chinese Subsidiaries: The Importance of Groups and Personal Networks Accepted for publication in Journal of Knowledge Management.

2003-10: Volker Mahnke, Torben Pedersen and Markus Verzin: The impact of knowledge management on MNC subsidiary performance: the role of absorptive capacity CKG Working Paper.

2003-11: Tomas Hellström and Kenneth Husted: Mapping Knowledge and Intellectual Capital in Academic Environments: A Focus Group Study Accepted for publication in Journal of Intellectual Capital CKG Working Paper.

2003-12: Nicolai J Foss: Cognition and Motivation in the Theory of the Firm: Interaction or "Never the Twain Shall Meet"? Accepted for publication in Journal des Economistes et des Etudes Humaines CKG Working Paper.

2003-13: Dana Minbaeva and Snejina Michailova: Knowledge transfer and expatriation practices in MNCs: The role of disseminative capacity.

2003-14: Christian Vintergaard and Kenneth Husted: Enhancing selective capacity through venture bases. 


\section{4}

2004-1: Nicolai J. Foss: Knowledge and Organization in the Theory of the Multinational Corporation: Some Foundational Issues

2004-2: Dana B. Minbaeva: HRM practices and MNC knowledge transfer

2004-3: Bo Bernhard Nielsen and Snejina Michailova: Toward a phase-model of global knowledge management systems in multinational corporations

2004-4: Kirsten Foss \& Nicolai J Foss: The Next Step in the Evolution of the RBV: Integration with Transaction Cost Economics

2004-5: Teppo Felin \& Nicolai J. Foss: Methodological Individualism and the Organizational Capabilities Approach

2004-6: Jens Gammelgaard, Kenneth Husted, Snejina Michailova: Knowledge-sharing Behavior and Post-acquisition Integration Failure

2004-7: Jens Gammelgaard: Multinational Exploration of Acquired R\&D Activities

2004-8: Christoph Dörrenbächer \& Jens Gammelgaard: Subsidiary Upgrading? Strategic Inertia in the Development of German-owned Subsidiaries in Hungary

2004-9: Kirsten Foss \& Nicolai J. Foss: Resources and Transaction Costs: How the Economics of Property Rights Furthers the Resource-based View

2004-10: Jens Gammelgaard \& Thomas Ritter: The Knowledge Retrieval Matrix: Codification and Personification as Separate Strategies

2004-11: Nicolai J. Foss \& Peter G. Klein: Entrepreneurship and the Economic Theory of the Firm: Any Gains from Trade?

2004-12: Akshey Gupta \& Snejina Michailova: Knowledge Sharing in Knowledge-Intensive Firms: Opportunities and Limitations of Knowledge Codification

2004-13: Snejina Michailova \& Kate Hutchings: Knowledge Sharing and National Culture: A Comparison Between China and Russia

\section{5}

2005-1: Keld Laursen \& Ammon Salter: My Precious - The Role of Appropriability Strategies in Shaping Innovative Performance

2005-2: Nicolai J. Foss \& Peter G. Klein: The Theory of the Firm and Its Critics: A Stocktaking and Assessment

2005-3: Lars Bo Jeppesen \& Lars Frederiksen: Why Firm-Established User Communities Work for Innovation: The Personal Attributes of Innovative Users in the Case of Computer-Controlled Music

2005-4: Dana B. Minbaeva: Negative Impact of Hrm Complementarity on Knowledge Transfer in Mncs

2005-5: Kirsten Foss, Nicolai J. Foss, Peter G. Klein \& Sandra K. Klein: Austrian Capital Theory and the Link Between Entrepreneurship and the Theory of the Firm 
2005-1: Nicolai J. Foss: The Knowledge Governance Approach

2005-2: Torben J. Andersen: Capital Structure, Environmental Dynamism, Innovation Strategy, and Strategic Risk Management

2005-3: Torben J. Andersen: A Strategic Risk Management Framework for Multinational Enterprise 